IZA DP No. 10167

The Heterogeneous Impacts of Business Cycles on Educational Attainment

Ernest Boffy-Ramirez

August 2016

Forschungsinstitut zur Zukunft der Arbeit Institute for the Study of Labor 


\title{
The Heterogeneous Impacts of Business Cycles on Educational Attainment
}

\author{
Ernest Boffy-Ramirez \\ University of Colorado Denver \\ and IZA
}

\author{
Discussion Paper No. 10167 \\ August 2016
}

\author{
IZA \\ P.O. Box 7240 \\ 53072 Bonn \\ Germany \\ Phone: +49-228-3894-0 \\ Fax: +49-228-3894-180 \\ E-mail: iza@iza.org
}

\begin{abstract}
Any opinions expressed here are those of the author(s) and not those of IZA. Research published in this series may include views on policy, but the institute itself takes no institutional policy positions. The IZA research network is committed to the IZA Guiding Principles of Research Integrity.

The Institute for the Study of Labor (IZA) in Bonn is a local and virtual international research center and a place of communication between science, politics and business. IZA is an independent nonprofit organization supported by Deutsche Post Foundation. The center is associated with the University of Bonn and offers a stimulating research environment through its international network, workshops and conferences, data service, project support, research visits and doctoral program. IZA engages in (i) original and internationally competitive research in all fields of labor economics, (ii) development of policy concepts, and (iii) dissemination of research results and concepts to the interested public.
\end{abstract}

IZA Discussion Papers often represent preliminary work and are circulated to encourage discussion. Citation of such a paper should account for its provisional character. A revised version may be available directly from the author. 
IZA Discussion Paper No. 10167

August 2016

\section{ABSTRACT}

\section{The Heterogeneous Impacts of Business Cycles on Educational Attainment}

In this study I examine the impact of fluctuations in the unemployment rate before high school graduation on educational attainment measured 30 years later. I find evidence that educational attainment is countercyclical, as found in other studies, but also find that the impact of the unemployment rate varies across the ability distribution. Using data from the 1979 National Longitudinal Survey of Youth, this analysis identifies individuals who are on the boundary between pursuing and not pursuing additional education. Exposure to a higher unemployment rate at age 17 is associated with higher educational attainment for men in the 60-80th quintile of the ability distribution. There is little to no evidence of an effect beyond this quintile - highlighting the heterogeneous impacts of higher unemployment on educational attainment.

JEL Classification: $\quad$ I2, I22, J1, J18, J24

Keywords: educational attainment, unemployment, heterogeneous impacts, ability distribution

Corresponding author:

Ernest Boffy-Ramirez

Department of Economics

University of Colorado

1380 Lawrence Street, Suite 470

Denver, CO 80204

USA

E-mail: ernest.boffy-ramirez@ucdenver.edu 


\section{Introduction}

During periods of poor labor market conditions, job possibilities are scarce and wages are stagnant, decreasing the opportunity cost of pursuing education. Yet, direct costs may increase and the financial means available to fund additional education may decline. Previous studies have found that college education is countercyclical- that is, higher unemployment rates are associated with increased educational attainment (Betts and McFarland 1995; Dellas and Sakellaris 2003). ${ }^{1}$

Using data from the 1979 National Longitudinal Survey of Youth (NLSY79), I explore the impact of exposure to a higher unemployment rate at age 17 on educational attainment, measured 30 years later. The NLSY79 includes detailed information on the educational history of each individual and an ability measure based on the Armed Forced Qualifying Test (AFQT) score. Between 1974 and 1982, U.S. national and state unemployment rates were volatile, creating sizeable variation across cohorts and within states over time.

This study differs from previous research by revealing heterogeneity within the ability distribution. Intuitively, it is unlikely that a high unemployment rate will have the same impact on individuals of different abilities. For example, the highest ability individuals may pursue additional education regardless of the unemployment rate they experience during high school. At the bottom end of the distribution, poor labor market conditions may not create strong enough incentives to change educational decisions. However, between these extremes, higher unemployment rates may push individuals who are on a margin between

\footnotetext{
${ }^{1}$ For more evidence of countercyclicality see Corman (1983), Kane (1994), and Berger and Kostal (2002). Other studies find that the relationship can differ by gender, undergraduate major, degree level, race, and country of origin (Bedard and Herman 2006; Black and Sufi 2002; Card and Lemieux 2000; Sakellaris and Spilimbergo 2000).
} 
educational choices to pursue more education when they might not have otherwise.

The empirical analysis suggests unemployment rates impact educational attainment countercyclically, but this impact is concentrated in the 60-80th AFQT ability quintile. Specifically, a 1 percentage point increase in the unemployment rate is associated with approximately a .11 increase in years of education for men in the 60-80th ability quintile. These results are robust to a number of specifications, providing strong evidence of heterogeneity. There is nearly no evidence of significant associations outside of the $60-80$ th quintile. ${ }^{2}$

\section{Data}

Information on educational attainment, family background characteristics, and AFQT score are drawn from the NLSY79 for nine distinct birth-year cohorts. Each individual is matched with the national and state unemployment rate they experienced at age 17 . In 2010, individual accumulated years of education attained is measured. Table 1 details the age range of each cohort, the size of each cohort measured in 1979, the national unemployment rate that year, and the average educational attainment of each cohort in 2010. Unemployment rates are provided by the Bureau of Labor Statistics (BLS).

AFQT score is a frequently used proxy for cognitive ability (Farber and Gibbons 1996; Neal and Johnson 1996). When the test was administered in 1980, the ages of participants ranged from 15 to 23 years old. Older participants may have accumulated post-high school job experience or postsecondary education, so AFQT scores are standardized by age group

\footnotetext{
${ }^{2}$ These findings are relevant to the literature investigating the impact of unfavorable economic conditions at job market entry on long-term earnings (Kahn 2010; Oreopoulos et al. 2012; Stevens 2008; Kwon et al. 2010; Brunner and Kuhn 2014; Oyer 2006, 2008; and Genda et al. 2010).
} 
(Altonji and Pierret 2001). Out of 12,686 respondents, 11,878 have a valid AFQT score. Summary statistics and confirmation of the standardization are reported in Table 2 . Table 2 shows are no differences in the demographic characteristics of individuals of the full sample and the sample with only valid AFQT scores.

The outcome of interest is the total years of education completed, measured as the highest grade completed by $2010 .^{3}$ Resource measures are included to control for differential access to education. Family resource controls include the highest grade completed by the individual's mother and father in 1979, the occupation and work status of each parent when the individual was 14, and the number of siblings in 1979. Parental characteristics are likely to be indicative of the available resources at age 17, so these variables will partially control for an individual's ability to pay for education.

Data on the average 2-year and 4-year in-state public university tuition by state and year is based on the U.S. Department of Education's National Center for Education Statistics Higher Education General Information Surveys. ${ }^{4}$ Data on the average Pell grant award by state and year (total Pell spending divided by number of recipients) is collected from the U.S. Department of Education's annual Basic Educational Opportunity Grant Program data books. These variables provide approximate the cost of the first year of college and financial aid.

To identify the effect of a change in the unemployment rate separate from other factors that influence the opportunity cost, two measures of outside wage offers are included. The

\footnotetext{
${ }^{3}$ Degree attainment is an alternative measure (Hungerford and Solon 1987; Belman and Heywood 1991), unfortunately, the NLSY79 is ill-suited to investigate this outcome. Constructing a measure of "highest degree ever attained" looking across all years of data, $18 \%$ of values are missing.

${ }^{4} 8$ years of data is made available by the Inter-university Consortium for Political and Social Research. The final year is available from Cornell University's Institute for Social and Economic Research.
} 
first is the nominal federal or state minimum wage, and the second is the average hourly wage for production workers in manufacturing. ${ }^{5}$ The NLSY79 reports suggestive evidence that outside wage offers can change an individual's willingness to enter the labor market. The NLSY79 asked individuals from one cohort whether they would accept hypothetical job offers at multiple wage rates. The percentage of respondents who answered "yes" to accepting a hypothetical job offer dramatically increases as the wage offer increases, regardless of the job description. ${ }^{6}$

\section{$3 \quad$ Empirical strategy \& results}

The empirical analysis focuses on men. It is not immediately clear why men and women will respond to high unemployment in the same way. Looking as far back as 1980, Hoynes, Miller, and Schaller (2012) find that a higher state unemployment rate effects men more than women- regardless of their race. They attribute this to men being more likely to work in industries that experience larger cyclical fluctuations, like construction and manufacturing. In addition to industry composition, womens' relationship to the labor market was changing dramatically. Between 1974 and 1983, labor force participation rose from 63.1 to $69.9 \%$ for women ages 20-24, and rose from 52.6 to $69 \%$ for women ages $25-34$. For men in the same age ranges labor force participation was relatively constant (Organization for Economic Co-operation and Development 2014).

\footnotetext{
${ }^{5}$ Minimum wage data is from the U.S. Department of Labor. It is not clear whether 17 year olds observe real or nominal rates. In state specifications with cohort fixed-effects this is not a concern. For details about how the average manufacturing wage is calculated in the Current Population Survey, refer to the data appendix.

${ }^{6}$ More details are provided in the appendix.
} 


\subsection{Model using national rates}

Model (1) presents the specification used to estimate the relationship between the national unemployment rate and years of education

$$
e d u c_{i y}=\alpha+\beta \cdot \text { rate }_{y}+\gamma \cdot A F Q T_{i}+X_{i y}^{\prime} \theta+\varepsilon_{i y}
$$

where educ is years of education for individual $i$ from cohort $y$ accumulated by 2010 and rate is the national unemployment rate corresponding to cohort $y$ at age 17 . Cohorts $y=$ $\{1,2,3, \ldots, 9\}$ span the years 1974-1982. AFQT is standardized individual AFQT score.

The vector $X$ includes the highest grade completed by the individual's mother and father in 1979, indicators for the work status of each parent when the individual was age 14, the occupation of each parent in 1979 if they were working (indicators cover 13 occupational categories), the number of siblings in 1979 (indicators from 0 to 8 and above), average 2year and 4-year in-state public university tuition, average Pell grant award amount, the federal minimum wage, and the average hourly manufacturing wage for production workers. Standard errors are clustered by cohort.

Identifying variation comes from yearly fluctuations in the unemployment rate. The expectation is that the unemployment rate will only influence individuals at or near the margin of two educational choices, so in a second set of specifications, separate regressions are run for each AFQT quintile to locate heterogeneous responses to the unemployment rate. AFQT score is also included in each quintile specification. 


\subsection{Model using state rates}

The NLSY79 state identifiers are used to match individuals with their state of residence. ${ }^{7}$

By doing this, the empirical analysis can identify the impact of the unemployment rate using within-state variation, netting out state-specific fixed unobservables that may lead to differential educational attainment.

Model (2) is the specification used to estimate the impact of the state unemployment rate on educational attainment

$$
\text { educ }_{i s y}=\alpha+\beta \cdot \text { rate }_{s y}+\gamma \cdot A F Q T_{i}+\sum \sigma_{s} \cdot \text { state }_{s}+\sum \tau_{y} \cdot \text { year }_{y}+X_{i s y}^{\prime} \theta+\varepsilon_{i s y}
$$

where educ is total educational attainment for individual $i$ in state $s$ from cohort $y$ accumulated by 2010 and rate is the unemployment rate in the state of residence at age 17.8 Controls for standardized AFQT and state and cohort fixed-effects are included. Cohort fixed-effects control for national trends in educational attainment that impact all individuals within a given year.

The vector $X$ includes all the same measures mentioned earlier, but national-level covariates are substituted for state-level covariates. ${ }^{9}$ Standard errors are clustered by state.

\subsection{Estimation results}

Estimates of model (1) are presented in the first four columns of Table 3. Only the specification with all of the available controls included reports statistical significant. The positive

\footnotetext{
${ }^{7}$ See the data appendix for more information on the NLSY79 Geocodes.

${ }^{8}$ Appendix Table A lists the highest and lowest unemployment rates in each state.

${ }^{9}$ State-level average Pell grant award is not available for year 1973-1974. Specifications run without average Pell grant award are not qualitatively different.
} 
coefficients follow Betts and McFarland (1995), Dellas and Sakellaris (2003), and Kahn (2010) suggesting educational decisions are countercyclical. No other point estimate is significant. A 1 percentage point increase in the unemployment rate is associated with an increase of about .086 years of education for men. AFQT score enters the regression with a positive and statistically significant coefficient. A 1 standard deviation increase in AFQT score relative to their cohort (within a range of approximately 4.55) is associated with either a 1.47 or 1.153 increase in years of completed education.

The right columns of Table 3 report the estimation results based on model (2) using the state unemployment rate. The coefficients on the state unemployment rate are smaller compared to the national coefficients and none are statistically different from 0 . For the specification with the largest coefficient, a 1 percentage point increase in the state unemployment rate is only associated with a .024 increase in years of education. AFQT is significant and consistent across specifications- closely mirroring the national results.

\subsection{Results by AFQT quintile}

The impact of higher unemployment is likely to have different effects within the AFQT distribution thus, models (1) and (2) are estimated by quintile of the AFQT distribution. Table 4 reports the results for both national and state unemployment rates. Each estimate is calculated from a separate regression in which all available controls are included. ${ }^{10}$

Table 4 shows that estimating an average association using the entire AFQT distribution masks interesting and statistically significant heterogeneity. Controlling for AFQT, parental characteristics, proxies for costs of college, and the value of outside offers, a 1 percentage

\footnotetext{
${ }^{10}$ Using AFQT quantiles corroborate the quintile results. Decile results are qualitatively similar.
} 
point increase in the national unemployment rate is associated with a statistically significant increase of about 0.107 years of education for men in the $60-80$ th quintile of the distribution. The impact is larger for the highest quintile but also less precise. Considering that the unemployment rate jumped two percentage points twice during the sample period, the magnitude of the association is noteworthy.

The results in the state-level analysis are starker. Only the coefficient in the 60-80th quintile is significant and positive, while the other coefficients are smaller and negative. A 1 percentage point increase in state unemployment rate is associated with an increase of about 0.109 years of education for men in the $60-80$ th quintile. Removing the contemporaneous controls likely to be correlated with the unemployment rate produces a similar estimate of .132. If only family background controls and AFQT score are included, the coefficient is .085. Both of these alternative estimates are significant at the $5 \%$ level. The estimate is robust to the exclusion of the controls and fixed-effects.

The 60-80th quintile coefficient in the state-level specification is almost the same as the estimate from the national-level model. Together, the national and state results indicate individuals in the 60-80th quintile of the ability distribution are the ones who are "tipped" towards attaining additional education when they experience a high unemployment rate at age 17 .

\subsection{Conclusion}

Examining the impact of unemployment rates on educational attainment across the ability distribution uncovers important heterogeneity masked by estimating an average effect. For 
men, the unemployment rate has an impact on the 60-80th quintile of the ability distribution. This result is robust to a number of specifications and consistent whether we use national or state unemployment rates. In addition, there is weak evidence of an effect in highest quintile.

This research moves beyond the studies that focus on contemporaneous associations, while also addressing the issue of strategic labor market entry. Unlike endogenous college graduation decisions or graduate school enrollment decisions, a key advantage of using the unemployment rate at age 17 is that individuals cannot easily delay graduation in periods of worsening economic conditions.

The funding of education at the post-secondary level could better address the shifts in demand during recessions by targeting individuals on the margin between educational decisions. Furthermore, it may be valuable for educational institutions and prospective employers to have knowledge of what types of individuals are incentivized to pursue additional education during periods of high unemployment.

Future work should focus on women. Historically, recessions have affected men and women differently. Based on the occupational distributions of men and women at the time, it is unlikely the results are the same for women. Increasing rates of college attendance and labor force participation during this period further differentiates women from men. 


\section{References}

[1] Altonji, Joseph G. and Charles R. Pierret. 2001. "Employer Learning and Statistical Discrimination", The Quarterly Journal of Economics, 116(1): 313-350.

[2] Bedard, Kelly and Douglas Herman. 2006. "Who Goes to Graduate/Professional School? The Importance of Economic Fluctuations, Undergraduate Field, and Ability," Economics of Education Review, 27(2): 197-210.

[3] Belman, Dale and John Heywood. 1991. "Sheepskin Effects in the Return to Education: An examination on Women and Minorities," Review of Economics and Statistics, 73(4): 720-724.

[4] Berger, Mark C. and Thomas Kostal. 2002. "Financial Resources, Regulation, and Enrollment in US Public Higher Education," Economics of Education Review, 21(2): 101110.

[5] Betts, Julian R. and Laurel L. McFarland. 1995. "Safe Port in a Storm: The Impact of Labor Market Conditions on Community College Enrollments," Journal of Human Resources, 30(4): 741-765.

[6] Black, Sandra and Amir Sufi. 2002. "Who Goes to College? Differential Enrollment by Race and Family Background," NBER Working paper no. 9310.

[7] Brunner, Beatrice and Andreas Kuhn. 2014. "The Impact of Labor Market Entry Conditions on Initial Job Assignment and Wages," Journal of Population Economics, 27(3): 705-738.

[8] Card, David and Thomas Lemieux. 2000. "Dropout and Enrollment Trends in the PostWar Period: What Went Wrong in the 1970s?" in Jonathan Gruber, editor, An Economic Analysis of Risky Behavior Among Youth. Chicago: University of Chicago Press.

[9] Corman, Hope. 1983. "Postsecondary Education Enrollment Responses by Recent High School Graduates and Older Adults," Journal of Human Resources, 18(2): 247-267.

[10] Dellas, Harris and Plutarchos Sakellaris. 2003. "On the Cyclicality of Schooling: Theory and Evidence," Oxford Economic Papers, 55(1): 148-172

[11] Farber, Henry S. and Robert Gibbons. 1996. "Learning and Wage Dynamics," Quarterly Journal of Economics, 111(4): 1007-1047.

[12] Genda, Yuji, Ayako Kondo, and Souichi Ohta. 2010. "Long-Term Effects of a Recession at Labor Market Entry in Japan and the United States," Journal of Human Resources, 45(1):157-196.

[13] Hoynes, Hilary, Douglas L. Miller, and Jessamyn Schaller. 2012. "Who Suffers During Recessions?" Journal of Economic Perspectives, 26(3): 27-48

[14] Hungerford, Thomas and Gary Solon. 1987. "Sheepskin Effects in the Return to Education," Review of Economics and Statistics, 69(1): 175-177 
[15] Kahn, Lisa. 2010. "The Long-Term Labor Market Consequences of Graduating from College in a Bad Economy," Labour Economics, 17(2): 303-316.

[16] Kane, Thomas. 1994. "College Entry by Blacks Since 1970: The Role of College Costs, Family Background, and the Return to Education," Journal of Political Economy, 102(5): 878-911.

[17] Kwon, Illoong, Eva Meyersson Milgrom, and Seiwoon Hwang. 2010. "Cohort Effects in Promotions and Wages: Evidence from Sweden and the United States," Journal of Human Resources, 45(3): 772-808.

[18] Neal, Derek and William R. Johnson. 1996. "The Role of Premarket Factors in BlackWhite Wage Differences," Journal of Political Economy, 104(5): 869-895.

[19] Oreopoulos, Philip, Till von Wachter, and Andrew Heisz. 2012. "The Short- and LongTerm Career Effects of Graduating in a Recession", American Economic Journal: Applied Economics, 4(1): 1-29.

[20] Organization for Economic Co-operation and Development. 2014. Labor Force Statistics (Paris: OECD), http://stats.oecd.org/Index.aspx?DataSetCode=LFS_SEXAGE_I_R

[21] Oyer, Paul. 2008. "The Making of an Investment Banker: Macroeconomic Shocks, Career Choice and Lifetime Income," Journal of Finance, 63(6): 2601-2628.

[22] Oyer, Paul. 2006. "Initial Labor Market Conditions and long-Term Outcomes for Economists," The Journal of Economic Perspectives, 20(3): 143-160.

[23] Rosen, Sherwin. 1977. "Human Capital: A Survey of Empirical Research," in Ronald Ehrenberg, editor, Research in Labor Economics (Volume 1). Greenwich: JAI Press.

[24] Sakellaris, Plutarchos and Antonio Spilimbergo. 2000. "Business Cycles and Investment in Human Capital: International Evidence on Higher Education," Carnegie-Rochester Conference Series on Public Policy, 52(1): 221-256.

[25] Stevens, Katrien. 2008. "Adverse Economic Conditions at Labour Market Entry: Permanent Scars or Rapid Catch-up?" Mimeo, University of Sydney. 
Table 1. Cohort age distribution \& national unemployment rate

\begin{tabular}{ccccccccccccc}
\hline \hline & Year & 1974 & 1975 & 1976 & 1977 & 1978 & 1979 & 1980 & 1981 & 1982 & 2010 & \\
National rate $\%$ & 5.6 & 8.5 & 7.7 & 7.1 & 6.1 & 5.8 & 7.1 & 7.6 & 9.7 & & \\
\hline Cohort, $y$ & $n$ & & & & & & & & & & & Avg. edu \\
1 & 437 & 17 & 18 & 19 & 20 & 21 & 22 & 23 & 24 & 25 & 53 & 13.29 \\
2 & 1,690 & 16 & 17 & 18 & 19 & 20 & 21 & 22 & 23 & 24 & 52 & 13.33 \\
3 & 1,666 & 15 & 16 & 17 & 18 & 19 & 20 & 21 & 22 & 23 & 51 & 13.26 \\
4 & 1,677 & 14 & 15 & 16 & 17 & 18 & 19 & 20 & 21 & 22 & 50 & 13.02 \\
5 & 1,633 & & 14 & 15 & 16 & 17 & 18 & 19 & 20 & 21 & 49 & 12.98 \\
6 & 1,508 & & & 14 & 15 & 16 & 17 & 18 & 19 & 20 & 48 & 13.25 \\
7 & 1,561 & & & & 14 & 15 & 16 & 17 & 18 & 19 & 47 & 13.19 \\
8 & 1,563 & & & & & 14 & 15 & 16 & 17 & 18 & 46 & 13.15 \\
9 & 950 & & & & & & 14 & 15 & 16 & 17 & 45 & 13.23 \\
\hline
\end{tabular}

Notes: Cohort 1 is the oldest cohort and cohort 9 the youngest. At the time of the first survey in 1979, cohort 1 is 22 years old and cohort 9 is 14 years old. Cohort 1 faced a national unemployment rate of 5.6 when they were 17 years old in 1974, and in 2010 had on average 13.29 years of education. Cohort 9 faced an unemployment rate of 9.7 when it was 17 in 1982, and in 2010 had on average 13.23 years of education. 
Table 2. Characteristics of the sample

\begin{tabular}{lccccc}
\hline \hline & \multicolumn{2}{c}{ Men } & & \multicolumn{2}{c}{ Women } \\
& Full sample & Valid afqt & & Full sample & Valid afqt \\
\cline { 2 - 3 } \cline { 5 - 6 } Mean AFQT & & 0.00 & & & -0.00 \\
St.dev. AFQT & 17.88 & 17.82 & & 17.91 & 17.88 \\
Mean age in 1979 & 12.99 & 13.06 & & 13.37 & 13.43 \\
Avg. completed yrs. & 68.39 & 68.58 & & 72.88 & 72.65 \\
Urban (\%) & 3.67 & 3.67 & & 3.70 & 3.71 \\
Avg. siblings & 11.00 & 11.04 & & 10.89 & 10.90 \\
Father completed yrs. & 10.94 & 10.97 & & 10.80 & 10.82 \\
Mother completed yrs. & 6,403 & 5,951 & & 6,283 & 5,927 \\
$n$ & & & & & \\
\hline
\end{tabular}

Notes: AFQT scores are standardized by cohort and calculated. Educational attainment is determined by looking at an individual's entire history ending by 2010. Urban, siblings, and parental education are all documented at the time when the individual was first surveyed in 1979. 
Table 3. Years of completed education \& the unemployment rate

\begin{tabular}{|c|c|c|c|c|c|c|c|c|c|}
\hline & \multicolumn{4}{|c|}{ National rate } & \multicolumn{5}{|c|}{ State rate } \\
\hline & $\mathrm{i}$ & ii & iii & iv & $\mathrm{i}$ & ii & iii & iv & $\mathrm{v}$ \\
\hline \multirow[t]{2}{*}{ Rate } & .057 & .064 & .050 & $.086^{* *}$ & .020 & .024 & .019 & .010 & -.000 \\
\hline & $(.489)$ & $(.045)$ & $(.033)$ & $(.030)$ & $(.033)$ & $(.024)$ & $(.022)$ & $(.035)$ & $(.037)$ \\
\hline \multirow[t]{2}{*}{ AFQT } & & $1.470^{* * *}$ & $1.153^{* * *}$ & $1.153^{* * *}$ & & $1.442^{* * *}$ & $1.143^{* * *}$ & $1.191^{* * *}$ & $1.203^{* * *}$ \\
\hline & & $(.019)$ & $(.023)$ & $(.024)$ & & $(.042)$ & $(.028)$ & $(.028)$ & $(.031)$ \\
\hline Family controls & & & $\mathrm{x}$ & $\mathrm{x}$ & & & $\mathrm{x}$ & $\mathrm{x}$ & $\mathrm{x}$ \\
\hline Fixed-effects & & & & & & & & $\mathrm{x}$ & $\mathrm{x}$ \\
\hline Cost controls & & & & $\mathrm{x}$ & & & & & $\mathrm{x}$ \\
\hline$n$ & 6,357 & 5,913 & 5,913 & 5,913 & 6,166 & 5,757 & 5,757 & 5,757 & 5,037 \\
\hline
\end{tabular}

Notes: * indicates significance at the $10 \%$ level; ** at the $5 \%$ level; and $* * *$ at the $1 \%$ level. Family controls are siblings, parental education, parental labor force status, and parental occupation. Cost controls are average in-state tuition at public universities, average Pell grant award amount, the federal or state minimum wage, and the average wage of production manufacturing workers. Standard errors are clustered by cohort in the national-level specifications and by state in the state-level specifications. 
Table 4. Years of completed education \& the unemployment rate by AFQT quintile

\begin{tabular}{lcc|cc}
\hline \hline & \multicolumn{3}{|c|}{ National } & \multicolumn{2}{|c}{ State } \\
AFQT quintile & Rate & $n$ & Rate & $n$ \\
\hline 0-20th & .062 & 1,286 & -.011 & 1,062 \\
& $(.071)$ & & $(.070)$ & \\
20-40th & .090 & 1,128 & -.050 & 995 \\
& $(.051)$ & & $(.053)$ & \\
40-60th & -.005 & 1,105 & -.032 & 962 \\
& $(.032)$ & & $(.088)$ & \\
$60-80 t h$ & $.107^{* *}$ & 1,149 & $.109^{*}$ & 966 \\
& $(.038)$ & & $(.059)$ & \\
80-100th & $.167^{*}$ & 1,245 & -.045 & 1,052 \\
& $(.077)$ & & $(.080)$ & \\
\hline
\end{tabular}

Notes: * indicates significance at the $10 \%$ level; ** at the $5 \%$ level; and *** at the $1 \%$ level. The coefficients reported are average marginal associations with standard errors below. All regressions include controls for AFQT, siblings, parental education, parental labor force status and occupation, average in-state tuition at public universities, average Pell grant award amount, the federal or state minimum wage, and the average wage of production manufacturing workers in the state. Statelevel regressions include state and year fixed-effects. Standard errors are clustered by cohort in the national-level specifications and by state in the state-level specifications. 


\section{Appendix}

\subsection{National Longitudinal Survey of Youth 1979}

The survey is a nationally representative sample of civilian, military, and minority or disadvantaged populations consisting of 6,403 men and 6,283 women between the ages of 14 and 22 at the time of their first interview in 1979. Follow-up surveys were conducted annually until 1994, after which participants were interviewed every other year.

Three subsamples comprise the NLSY79. A cross-sectional sample of 6,111 respondents represent non-institutionalized civilians. A supplemental sample of 5,295 civilian Hispanic or Latino, black, and economically disadvantaged non-black/non-Hispanic respondents. A sample of 1,280 respondents represent the population serving in the U.S. military.

\subsection{State unemployment rates}

The BLS historical database of state model-based estimates is limited to 1976 and later. During the early 1970s, BLS first undertook efforts to supplement the state CPS samples. Prior to that, each state's sample was a by-product of the national sample. The less populous states had very small samples- far too small for reliable estimation. Annual-average estimates from the CPS date back to 1970 for about half of the states (the larger ones). For smaller states, it is believed that there are no reliable or comparable data for the 1970-75 period (see www.gpo.gov/libraries/ for more information).

\subsection{Average manufacturing wages 1974-1982}

Data is acquired through the University of Minnesota's Integrated Public Use Microdata Series and calculated from the March Supplement of the Current Population Survey (CPS). Product manufacturing is defined along industry codes designated by the North American Industry Classification System (NAICS). According to the NAICS, "The Manufacturing sector comprises establishments engaged in the mechanical, physical, or chemical transformation of materials, substances, or components into new products. Establishments that transform materials or substances into new products by hand or in the worker's home and those engaged in selling to the general public products made on the same premises from which they are sold, may also be included in this sector" (http://www.bls.gov/iag/tgs/iag31-33.htm).

The average wage is defined as current total yearly wage and salary income divided by weeks worked and weekly hours worked. Income values of 0 or 1 and top-coded values are omitted. CPS provided weights are applied to adjust for the sampling design. In the years 1974, 1975, and 1976, only a selection of states are available. For the rest of the states their region-division average must be used. Those divisions are: New England, Middle Atlantic, 
East North Central Division, West North Central Division, South Atlantic Division, East South Central, West South Central Division, Mountain Division, and Pacific.

\subsection{Hypothetical wage offer questions}

A unique feature of the NLSY79 data is that it asks questions that aim to quantify an individuals' willingness to work. NLSY79 respondents were asked whether they would accept a hypothetical job offer at multiple wage rates. The question states, "If (next summer/right now) you were offered a full-time job at $(\$ 2.50 / \$ 3.50 / \$ 5.00 \mathrm{hr})$, do you think you would accept it?" If a respondent answer no to the first offer of $\$ 2.50$, the wage offer increases to the next highest level. The wage offer is not increased for respondents who accept an offer. Low wage offers make entering the labor market less attractive, lowering the opportunity cost of additional education. Asking how respondents would withhold labor is one way to observe the salience of opportunity costs in the decision-making processes of 17 year olds.

The percentage of 17 year old respondents who answered "yes" to accepting a hypothetical job offers in 1979 increases dramatically when the wage offer goes from $\$ 2.50 / \mathrm{hr}$. to $\$ 5.00 / \mathrm{hr}$., regardless of the job type.

When respondents are grouped into AFQT quintiles, the percentage accepting hypothetical wage offers show differences by cognitive ability. For example, only $15.69 \%$ of the lowest quintile would reject $\$ 5.00 / \mathrm{hr}$. for washing dishes, while $33.92 \%$ of the highest quintile would reject the same offer. These questions provide suggestive evidence that 17 year olds facing high school graduation are responsive to changes in outside wage offers and that responses differ by AFQT quintile.

\subsection{NLSY79 state identifiers}

The NLSY79 reports the state of residence at age 14 for almost all individuals in the sample. State of residence at age 17 is only observed for 5,582 individuals (specifically for individuals ages 14-17 in 1979), so I use state of residence at age 14 for the remaining observations. Of the subsample with residence reported at both 14 and 17, about $93 \%$ report the same residence at both ages, suggesting that residence at age 14 is a good proxy for residence at age 17. Out of the sample of 5,346 observations with both a valid reported residence at 14 and 17, only 389 individuals report living in a different state at age 17 (7.28\% of the sample). I have no reason to believe mobility behavior of 18-22 years olds in 1979 is dramatically different when they were 14-17 years old. Furthermore, this group occupies a trivial portion of each quintile sample. 
Appendix Table A. State unemployment rates 1974-1982

\begin{tabular}{|c|c|c|c|c|c|c|c|}
\hline State & Low $\%$ & High $\%$ & $n$ & State & Low $\%$ & High $\%$ & $n$ \\
\hline Alaska & 6.8 & 10.6 & 31 & Montana & 5.2 & 8.2 & 90 \\
\hline Alabama & 5.5 & 13.2 & 389 & North Carolina & 4.5 & 9.5 & 465 \\
\hline Arkansas & 5.2 & 9.5 & 142 & North Dakota & 3.6 & 5.0 & 16 \\
\hline Arizona & 5.1 & 12.1 & 138 & Nebraska & 2.6 & 5.7 & 59 \\
\hline California & 6.3 & 10.0 & 1223 & New Hampshire & 3.8 & 9.1 & 19 \\
\hline Colorado & 4.1 & 7.8 & 220 & New Jersey & 6.3 & 10.5 & 477 \\
\hline Connecticut & 5.2 & 9.1 & 275 & New Mexico & 6.3 & 9.9 & 122 \\
\hline Delaware & 7.3 & 9.8 & 9 & Nevada & 4.8 & 9.9 & 18 \\
\hline Florida & 6.1 & 10.7 & 515 & New York & 6.4 & 10.2 & 900 \\
\hline Georgia & 5.2 & 8.6 & 448 & Ohio & 4.8 & 12.7 & 730 \\
\hline Hawaii & 5.1 & 9.3 & 13 & Oklahoma & 3.3 & 7.2 & 210 \\
\hline Iowa & 2.2 & 8.1 & 126 & Oregon & 6.1 & 11.6 & 60 \\
\hline Idaho & 5.1 & 9.0 & 10 & Pennsylvania & 5.1 & 11.3 & 538 \\
\hline Illinois & 4.2 & 11.3 & 399 & Rhode Island & 7.7 & 10.9 & 5 \\
\hline Indiana & 5.2 & 11.9 & 236 & South Carolina & 5.0 & 10.7 & 309 \\
\hline Kansas & 3.1 & 6.5 & 71 & South Dakota & 2.7 & 5.5 & 44 \\
\hline Kentucky & 4.9 & 10.8 & 47 & Tennessee & 5.1 & 11.7 & 239 \\
\hline Louisiana & 6.5 & 10.2 & 115 & Texas & 4.3 & 6.9 & 839 \\
\hline Massachusetts & 5.5 & 11.2 & 258 & Utah & 3.9 & 8.3 & 25 \\
\hline Maryland & 4.7 & 8.2 & 138 & Virginia & 4.5 & 7.4 & 263 \\
\hline Maine & 6.4 & 10.3 & 9 & Vermont & 4.9 & 9.4 & 52 \\
\hline Michigan & 7.1 & 15.6 & 600 & Washington & 6.7 & 11.8 & 157 \\
\hline Minnesota & 4.0 & 8.1 & 219 & Wisconsin & 4.5 & 10.3 & 379 \\
\hline Missouri & 4.6 & 9.2 & 307 & West Virginia & 6.0 & 14.3 & 174 \\
\hline Mississippi & 4.5 & 11.5 & 109 & $\mathrm{DC}$ & 6.7 & 10.6 & 86 \\
\hline
\end{tabular}

Notes: The table reports the highest and lowest unemployment rates during the years 1974-1982. There are no individuals residing in Wyoming. 